\title{
As caixas de histórias na visão de profissionais de saúde como estratégia de enfrentamento da hospitalização infantil**
}

\author{
The stories box behind the vision health \\ professionals as a strategy to coping \\ of infant hospitalization
}

\author{
Nathália Rodrigues Garcia', Luzia Iara Pfeifer², \\ Maria Paula Panúncio-Pinto ${ }^{3}$
}

GARCIA, N. R.; PFEIFER, L. I.; PANÚNCIO-PINTO, M. P. As caixas de histórias na visão de profissionais de saúde como estratégia de enfrentamento da hospitalização infantil. Rev. Ter. Ocup. Univ. São Paulo, v. 23, n. 2, p. 169-177, maio/ago. 2012.

RESUMO: O "Programa de Extensão Caixa de Histórias" é desenvolvido em enfermarias pediátricas, utilizando como recursos bonecos e outros elementos. Este estudo visa analisar a opinião de profissionais de saúde sobre o referido programa. Participaram do estudo 5 profissionais de saúde de uma Enfermaria Oncopediátrica, os quais responderam a um questionário sobre o impacto das "Caixas de Histórias" em crianças hospitalizadas. Utilizou-se para análise a técnica do discurso do sujeito coletivo. As respostas possibilitaram o seguinte discurso: "As histórias, e qualquer tipo de atividade lúdica e de recreação, auxiliam na recuperação da criança, pois permitem que esta se esqueça de seu sofrimento. Dessa forma, as crianças ficam mais a vontade, diminuindo o desconforto causado pelo ambiente hospitalar. Acreditamos que as histórias melhorem qualidade da internação, pois percebemos o quanto as crianças ficam mais animadas e o quanto elas se divertem no mundo da criatividade e imaginação. Por elas estarem mais animadas, a alegria delas é transmitida a nós. As histórias contadas nos ajudam na realização das nossas atividades, nos distraem e, desta forma, sorrimos com as crianças. Assim, o tempo passa sem elas perceberem".

DESCRITORES: Humanização da assistência; Equipe de assistência ao paciente; Oncologia/ recursos humanos; Criança; Pessoal da saúde/recursos humanos; Serviços de saúde da criança/ recursos humanos

\footnotetext{
* Este artigo é resultado da pesquisa realizada com o apoio do Conselho Nacional de Desenvolvimento Científico e Tecnológico - CNPq, sendo apresentada parte deste no XII Congresso Brasileiro de Oncologia Pediátrica, realizado em Curitiba, Paraná, nos dias 29 de setembro a 02 de outubro de 2010 e premiado como melhor pôster.

1. Mestranda da Escola de Enfermagem de Ribeirão Preto da Universidade de São Paulo.

2. Professora doutora da Divisão de Terapia Ocupacional da Faculdade de Medicina de Ribeirão Preto da Universidade de São Paulo.

3. Professora doutora da Divisão de Terapia Ocupacional da Faculdade de Medicina de Ribeirão Preto da Universidade de São Paulo. Endereço para correspondência: Luzia Iara Pfeifer. Secretaria do Departamento de Neurociências e Ciências do Comportamento da FMRP-USP. $4^{\circ}$ andar do HCFMRP-USP. Av. Bandeirantes, 3900. Bairro Monte Alegre. Ribeirão Preto, SP. CEP: 14.048-900. E-mail: luziara@fmrp.usp.br
} 


\section{INTRODUÇÃO}

hospitalização infantil ocasiona a ruptura
do cotidiano infantil, em função da rotina
hospitalar, faltas na escola, horários diferentes, visitas seletivas, separação, aspectos estes que podem levar a alterações físicas e emocionais (PEDROSA et al., 2007; PFEIFER; MITRE, 2008).

Cada criança vivencia e percebe seu adoecimento de modo diferente de acordo com seus valores e experiência (ADAM; HERZLICH, 2001), entretanto, não se pode negar que uma criança experimentará menos o mundo à sua volta se não forem criadas alternativas para que esta interação aconteça da forma mais prazerosa possível. Neste sentido, percebe-se a necessidade da utilização de recursos terapêuticos não medicamentosos para o enfrentamento da patologia e da hospitalização(PFEIFER; MITRE, 2008).

Para que os efeitos da hospitalização infantil sejam minimizados, é necessário deixar os ambientes hospitalares mais humanos e salientar a importância do brincar (PARCIANELLO; FELIN, 2008).

Neste contexto, o brincar aparece como um facilitador na transformação do cotidiano da hospitalização, fazendo com que a criança ultrapasse as barreiras do adoecimento (MITRE; GOMES, 2004), possibilitando a expressão de sentimentos, medos, por meio da elaboração de situações novas e/ou ameaçadoras de maneira mais adequada e menos traumática (MITRE, 2000).

Além disso, a humanização é importante no cenário da hospitalização infantil, já que respeita os direitos, a dignidade e valoriza as pessoas, garantindo um atendimento de qualidade (BACKES et al., 2006). No caso da assistência pediátrica, é fundamental a utilização de estratégias que valorizem as necessidades das crianças (LIMA et al., 2009).

Desta forma, as histórias infantis são reconhecidas como estratégias de humanização hospitalar, já que favorecem a diminuição de tensões, ansiedades, possibilitando o alívio da dor e proporcionando alegria e confiança para muitas crianças internadas (MORENO et al., 2003). Assim, as histórias podem acelerar a recuperação da criança e possibilitar a interação desta com os adultos e com os profissionais da saúde (GOUVEIA, 2003).

O Programa de Extensão "Caixa de Histórias" vem sendo desenvolvido, de forma sistemática, desde 2005 nas Enfermarias de Pediatria de um hospital universitário no interior de São Paulo, capacitando graduandos de Terapia Ocupacional para contar histórias infantis, utilizando como recursos bonecos e outros elementos lúdicos.

Os participantes do programa passam por uma capacitação inicial, a qual consiste em 25 horas de aulas teóricas e oficinas, envolvendo temas como: desenvolvimento infanto-juvenil; terapia ocupacional e áreas de desempenho na infância e adolescência; hospitalização; contos de fadas, histórias infantis e seu potencial terapêutico; oficinas de construção de caixas de histórias; musicalização.

Após esse processo, ocorre em duplas a escolha de uma história, a construção da caixa e a contação de histórias nos locais definidos. Após a contação das histórias, os personagens e os elementos da caixa são manipulados pelas crianças e adolescentes e são realizadas atividades de acordo com o tema da história.

Durante o desenvolvimento do programa são realizadas supervisões semanais com os participantes e os coordenadores para troca de informações e discussões das vivências.

Este programa tem se mostrado eficaz como estratégia de enfrentamento da hospitalização de crianças e adolescentes (PFEIFER et al., 2006; ALVES et al., 2007; GARCIA; PFEIFER, 2009), além de auxiliar na capacitação profissional dos alunos voluntários, através do desenvolvimento de estratégias que visam o acolhimento da criança e da família (SANTOS, 2008; PEREIRA et al., 2009).

Em pesquisa realizada com o objetivo de analisar as possibilidades da promoção do brincar em hospitais na percepção de profissionais de saúde que se utilizam desta ação, percebeu-se que houve reconhecimento da importância da utilização de estratégias lúdicas no ambiente hospitalar por parte de outros profissionais (chefes de equipe, gestores, entre outros). Além disso, a utilização do lúdico foi apontada como fundamental para a imagem projetada da instituição. Alguns benefícios que facilitaram a promoção do brincar no hospital foram: infra-estrutura do hospital, condições de trabalho adequadas, material disponível, bom espaço físico e remuneração (MITRE; GOMES, 2007).

Em estudo realizado com o objetivo de compreender, na visão de profissionais da saúde, o significado do uso do brincar/brinquedo em uma sala de espera de um ambulatório infantil, percebeu-se que: os profissionais reconheceram a importância do brincar/brinquedo, aproveitando melhor o tempo de espera; as brincadeiras podem contribuir para o desenvolvimento da criança; a brincadeira pode transformar o ambiente hospital em um local mais agradável; os entrevistados afirmaram que o profissional que utiliza o brincar para se aproximar da criança e para se comunicar com ela está mais preparado para lidar com esta clientela; o brincar proporcionou uma maior aceitação da criança durante procedimentos médicos e de enfermagem; o brincar/brinquedo pode melhorar a qualidade do cuidado 
prestado à criança e seu acompanhante; a brincadeira é importante para o profissional ganhar a confiança da criança (NASCIMENTO et al., 2011).

Desta forma, sendo o ambiente hospitalar um espaço que tem como objetivo o tratamento e a cura, utilizandose de medicação e procedimentos invasivos, torna-se importante identificar como os profissionais de saúde percebem a utilização de intervenções terapêuticas não invasivas junto a crianças com câncer internadas.

Portanto, o objetivo deste estudo foi identificar a visão de profissionais de saúde de uma enfermaria oncopediátrica em relação ao "Programa de Extensão Caixa de Histórias" no cuidado à criança hospitalizada.

\section{PROCEDIMENTOS METODOLÓGICOS}

A pesquisa foi realizada junto a profissionais de saúde que atuavam em uma Enfermaria Oncopediátrica de um Hospital Universitário no interior de São Paulo. Para participar deste estudo o profissional de saúde deveria ter presenciado e observado ao menos uma contação de história desenvolvida pelo "Programa de Extensão Caixa de Histórias" junto a uma criança internada na referida enfermaria. A partir deste critério de inclusão para participação, foram identificados 10 profissionais de saúde, os quais foram convidados e, destes, cinco aceitaram participar da pesquisa. Estes profissionais são considerados recentes neste local, tendo entre um a cinco anos de atuação nesta enfermaria. Maiores detalhes dos profissionais da pesquisa foram suprimidos a fim de preservar sua identidade por se tratar de uma enfermaria pequena, havendo facilidade no reconhecimento deles.

Os dados foram coletados a partir do preenchimento, por parte dos participantes, de um roteiro composto por questões abertas que englobaram a influência do "Programa de Extensão Caixa de Histórias" na recuperação da criança; a opinião sobre se o "Programa de Extensão Caixa de Histórias" pode ser considerado uma estratégia de enfrentamento da hospitalização; a melhoria ou não da aceitação das crianças aos procedimentos (curativos, medicações, exames) realizados pela equipe de enfermagem e médica após a contação da história; a influência das histórias contadas na diminuição do período de internação; a recomendação ou não desse tipo de programa em outras enfermarias de pediatria de outros hospitais e o impacto pessoal da presença do "Programa de Extensão Caixa de Histórias".

Os depoimentos foram devolvidos para as pesquisadoras através de correio eletrônico, pessoalmente ou através de envelope lacrado não identificado, possibilitando a liberdade de opinião por parte dos respondentes.

No presente estudo, procurou-se analisar as mensagens dos profissionais de saúde abordados utilizando os instrumentos de análise qualitativa, buscando identificar a idéia central contida nas falas e construindo o discurso do sujeito coletivo a partir destas. O discurso do sujeito coletivo (DSC) se utiliza de depoimentos coletados em pesquisas que possuem questões abertas para se chegar a um depoimento coletivo (LEFÉVRE et al., 2009).

Para a análise dos depoimentos dos profissionais, foram utilizadas três figuras metodológicas propostas por Lefréve et al. (2002): as Expressões-chave (EC), as quais se configuram nas transcrições literais de parte dos depoimentos, contínuos ou não, que permitem resgatar a sua essência; a Idéia central (IC) etapa em que se busca realizar a síntese do conteúdo discursivo explicitado pelos sujeitos; e, finalmente, a construção do DSC, momento no qual se busca somar os discursos, reconstruindo, a partir de trechos dos discursos individuais, tantos discursos homogêneos quantos se julgue necessários para expressar o pensamento daquele universo estudado sobre um fenômeno. Os depoimentos coletivos são escritos na primeira pessoa do singular para produzir o efeito de uma opinião coletiva, caracterizando as representações sociais (LEFRÉVE; LEFRÉVE, 2006).

A pesquisa seguiu todos os preceitos éticos da portaria 196/96, com aprovação no comitê de ética em pesquisa do referido hospital e tendo a assinatura do Termo de Consentimento Livre-Esclarecido por parte dos participantes.

\section{RESULTADOS E DISCUSSÃO}

A partir da leitura e releitura dos depoimentos dos profissionais de saúde foi possível identificar e elaborar 6 categorias de resposta sobre do "Programa de Extensão Caixa de Histórias" com suas idéias centrais entre parênteses: recuperação da criança (as histórias ajudam no tratamento da criança), hospitalização (o "Programa de Extensão Caixa de Histórias" facilita o enfrentamento da hospitalização pela criança), procedimentos médicos e de enfermagem (as histórias facilitam a realização de procedimentos médicos e de enfermagem), tempo de internação (as histórias contadas fazem com que a internação seja encarada de uma maneira positiva), alegria e distração para a criança (as histórias trazem alegria para as crianças e as distraem) e impacto pessoal (as histórias ajudam no trabalho da equipe de saúde). As categorias de respostas, as expressões-chave e as idéias centrais podem estão listadas na Tabela 1. 
Tabela 1 - Categorias de respostas, expressões-chave e idéias centrais colhidas a partir dos discursos

\begin{tabular}{|c|c|c|}
\hline $\begin{array}{l}\text { Categoria de } \\
\text { resposta }\end{array}$ & Expressões-chave & Idéias Centrais \\
\hline $\begin{array}{l}\text { Recuperação } \\
\text { da criança }\end{array}$ & $\begin{array}{l}\text { "Toda atividade lúdica e de recreação interfere positivamente no } \\
\text { andamento do tratamento". } \\
\text { "(..) contar histórias para as crianças da Onco interfere no } \\
\text { tratamento das mesmas. Pois naquele momento, elas esquecem } \\
\text { onde estão, esquecem o por quê de estar ali, suas dores, seus } \\
\text { medos são deixados de lado...". } \\
\text { "(...) faz a criança 'esquecer' um pouco sua internação". } \\
\text { "(...) a criança fica mais colaborativa (comunicativa)". }\end{array}$ & $\begin{array}{l}\text { As histórias ajudam no tratamento da } \\
\text { criança. }\end{array}$ \\
\hline Hospitalização & $\begin{array}{l}\text { "(...) mostra aspectos positivos no olhar da criança durante a } \\
\text { internação". } \\
\text { "(...) o ambiente hospitalar nem sempre representa conforto ao } \\
\text { paciente e após o programa, parece que as crianças ficam mais a } \\
\text { vontade". } \\
\text { "(...) o hospital deixa de ser aquele ambiente sem nada o que fazer } \\
\text { pra elas, de sofrimento e angústia". }\end{array}$ & $\begin{array}{l}\text { O "Programa de Extensão Caixa de } \\
\text { Histórias" facilita o enfrentamento da } \\
\text { hospitalização pela criança. }\end{array}$ \\
\hline $\begin{array}{l}\text { Procedimentos } \\
\text { médicos e de } \\
\text { enfermagem }\end{array}$ & $\begin{array}{l}\text { "(...) a compreensão ajuda muito na aceitação, mesmo assim, isso é } \\
\text { muito relativo, depende da criança". } \\
\text { "(...) a criança se sentindo mais feliz e menos tensa reage melhor } \\
\text { aos procedimentos". } \\
\text { "É mais fácil realizar procedimentos após as historias contadas. } \\
\text { Aproveitamos o momento e durante a realização de procedimentos, } \\
\text { perguntamos a elas o que ouviram.....sendo mais fácil distraí-las". } \\
\text { "(...) tudo fica mais fácil ao realizar os procedimentos". }\end{array}$ & $\begin{array}{l}\text { As histórias facilitam a realização de } \\
\text { procedimentos médicos e de enfermagem. }\end{array}$ \\
\hline $\begin{array}{l}\text { Tempo de } \\
\text { internação }\end{array}$ & $\begin{array}{l}\text { "(...) a medida que a criança aceita melhor os acontecimentos com } \\
\text { certeza a chance de diminuir o tempo de internação é maior, porém } \\
\text { assim de imediato não consigo garantir isso". } \\
\text { "Não. Acredito que melhorem a qualidade da internação". } \\
\text { "Desconheço". }\end{array}$ & $\begin{array}{l}\text { As histórias contadas fazem com que a } \\
\text { internação seja encarada de uma maneira } \\
\text { positiva. }\end{array}$ \\
\hline $\begin{array}{l}\text { Alegria e } \\
\text { distração para } \\
\text { a criança }\end{array}$ & 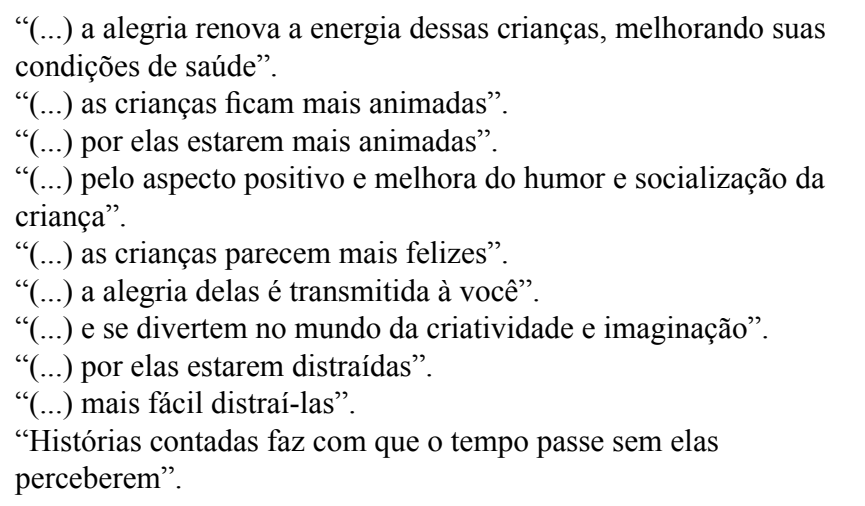 & $\begin{array}{l}\text { As histórias trazem alegria para as crianças. } \\
\text { As histórias distraem as crianças. }\end{array}$ \\
\hline $\begin{array}{l}\text { Impacto } \\
\text { pessoal }\end{array}$ & $\begin{array}{l}\text { “(...) temos a oportunidade de aproveitar a história contada para } \\
\text { nos ajudar na realização das nossas atividades”. } \\
\text { "(...) nos distrair durante o plantão". } \\
\text { "(...) sorrimos com elas". } \\
\text { "(...) necessito que a criança dialogue comigo, e após o programa, } \\
\text { elas ficam mais comunicativas". }\end{array}$ & $\begin{array}{l}\text { As histórias ajudam no trabalho da equipe } \\
\text { de saúde. }\end{array}$ \\
\hline
\end{tabular}




\section{Recuperação da criança}

As histórias, e qualquer tipo de atividade lúdica e de recreação, auxiliam na recuperação da criança, pois permitem que a criança se esqueça de seu sofrimento, fazendo com que colabore e se comunique mais.

Esse discurso mostra que os profissionais de saúde não reconhecem o "programa de extensão caixa de histórias" como um recurso terapêutico não medicamentoso, já que afirmam que qualquer atividade lúdica ou recreação possibilita a melhora do estado emocional da criança. O brincar é uma ocupação infantil significativa, fundamental (PARHAM; PRIMEAU, 2002) e necessária para um adequado desenvolvimento infantil (PAPALIA et al., 2006).

O brincar transforma o cotidiano da internação, já que, por meio do mundo real e imaginário, a criança ultrapassa os limites do adoecimento (MITRE; GOMES, 2004).

Uma estratégia utilizada no sentido de auxiliar a criança no processo de hospitalização é o uso do brinquedo terapêutico. As atividades espontâneas que levam ao prazer, mas que não alcançam um objetivo, constituem o brinquedo normativo. Já o brinquedo terapêutico precisa de um profissional qualificado para auxiliar a criança, podendo gerar um bem-estar físico e emocional. É necessário que o ambiente seja preparado com brinquedos, havendo técnicas específicas para sua aplicação (LEITE; SHIMO, 2007).

Portanto, a equipe de saúde é fundamental no desenvolvimento do brincar terapêutico, podendo criar condições para que a criança hospitalizada seja envolvida pelo imaginário, facilitando sua elaboração e aceitação (FONTES et al., 2010).

Nos últimos anos, os gestores de instituições hospitalares têm, de modo geral, valorizado e percebido a importância do brincar na hospitalização infantil (MITRE; GOMES, 2007). Em pesquisa realizada junto a 33 profissionais de saúde em três hospitais de diferentes regiões do Brasil, Mitre e Gomes (2004) identificaram a utilização do brincar como um importante instrumento de intervenção na hospitalização infantil, apesar de existirem diferentes tipos de abordagem e de uso da atividade lúdica.

No contexto hospitalar, as histórias contadas para crianças internadas permitem que estas se sintam em um ambiente menos hostil, esclarecendo, reanimando, desenvolvendo a vontade de cura, de retorno ao lar e a capacidade criativa, melhorando seu estado emocional, acelerando sua recuperação (GOUVEIA, 2003).

\section{Hospitalização}

As histórias contadas deixam as crianças mais a vontade, já que aquelas mostram aspectos positivos, diminuindo o desconforto causado pelo ambiente hospitalar.

D'Alcantara (2008), afirma que o desconforto pode levar ao aumento de iatrogenias, aumentando o cansaço e a irritabilidade dos familiares das crianças internadas, diminuindo, desta forma, seu limiar de tolerância, o que potencializa os efeitos da hospitalização infantil. Além disso, o sofrimento da criança hospitalizada não se restringe apenas ao aspecto físico. Assim, a intervenção dos profissionais de saúde precisa relacionar-se com as necessidades da criança, favorecendo seu bem-estar geral (D'ALCANTARA, 2008).

Por meio do discurso acima, percebe-se que as histórias infantis, quando selecionadas de forma adequada e contadas de modo adaptado para a criança que está ouvindo, podem ser utilizadas como estratégias positivas de enfrentamento da hospitalização infantil, diminuindo os efeitos causados por esta. Ao ler, contar ou ouvir histórias a criança amplia seu repertório sócio-cultural e seu universo intelectual, facilitando a elaboração de sentimentos (D'ALCANTARA, 2008). No caso de crianças com câncer as histórias são recursos terapêuticos com os quais elas costumam expressar preocupações, sentimentos e idéias sobre a morte (VALLE, 1997). Além disso, as histórias infantis possibilitam a interação da criança com os adultos e com os profissionais da saúde (GOUVEIA, 2003).

O fato do "Programa de Extensão Caixa de Histórias" possibilitar a participação das crianças durante a contação, modificando a história, explorando os elementos da caixa e realizando atividades após a história auxilia no enfrentamento da hospitalização.

\section{Procedimentos médicos e de enfermagem}

O "Programa Caixa de Histórias" faz com que as crianças fiquem mais felizes e menos tensas, facilitando a realização de procedimentos. Desta forma, aproveitamos o momento para distrai-las, enfim, tudo fica mais fácil com o programa. Mas, para aceitarem os procedimentos, as crianças precisam compreender o que está acontecendo.

No discurso acima, percebe-se que os profissionais de saúde relacionam o "Programa de Extensão Caixa de Histórias" como uma atividade que proporciona apenas a distração da criança. Eles identificam que as crianças cooperam com os procedimentos médicos e de enfermagem quando estão mais alegres e distraídas, entretanto não identificam o valor terapêutico não medicamentoso que 
este recurso pode proporcionar, apesar de acreditarem na importância do programa.

O brincar pode modificar a ordem hospitalar ao propor novos padrões de relação entre pacientes, equipe de saúde e familiares, levando à desconfiança e oposição por parte da equipe. Para muitos profissionais de saúde, o brincar é um ornamento, visto como algo que é feito quando todos os procedimentos ditos qualificados foram cumpridos, desvalorizando os efeitos terapêuticos dos procedimentos lúdicos (FORTUNA, 2004).

Em alguns momentos, os profissionais da saúde tendem a ver aquilo que está mais relacionado com sua categoria profissional e atividades de trabalho, esquecendose dos direitos da criança hospitalizada, tais como brincar, receber visitas, ter acompanhantes, ter conhecimento do seu tratamento, entre outros. A equipe de saúde, muitas vezes, preocupa-se com a parte técnica do cuidado e tal falta de preparo com os cuidados da criança prejudica a abordagem integral e a percepção de seu estado emocional (GOMES et al., 2010).

Por isso, os procedimentos médicos e de enfermagem exigem sensibilidade e técnica, considerando a percepção da criança sobre o procedimento realizado. Além disso, o profissional da saúde precisa compreender o mundo infantil (SOARES; VIEIRA, 2004).

O processo de tratamento da criança com câncer é longo, penoso e os procedimentos invasivos são considerados um importante elemento estressor (MICELI, 2005).

Em pesquisa realizada junto a três crianças préescolares submetidas à punção venosa percebeu-se que o preparo das crianças para punção venosa com utilização de brinquedo terapêutico foi positivo, já que estas ficaram mais cooperativas, demonstraram menos medo, compreenderam melhor o procedimento realizado, exteriorizaram seus sentimentos, elaboraram situações traumáticas e se relacionaram melhor com outras crianças e com a equipe (MARTINS et al., 2001). Neste estudo os profissionais da saúde abordados passaram a acreditar na importância do brinquedo terapêutico devido aos resultados obtidos.

Da mesma forma, notou-se que o "Programa de Extensão Caixa de Histórias" também aumentou a crença da equipe de saúde na importância dos recursos não medicamentosos, mesmo não reconhecendo o enquanto um recurso terapêutico.

\section{Tempo de internação}

As histórias fazem com que as crianças aceitem melhor os acontecimentos, mas não há como garantir que o tempo de internação diminua em decorrência desse fato. Mesmo desconhecendo o efeito das histórias contadas no periodo de internação, acreditamos que estas melhorem sua qualidade.

Apesar de perceberem a importância do "Programa de Extensão Caixa de Histórias" para a recuperação de crianças com câncer internadas, os profissionais de saúde do estudo não fizeram uma relação entre o programa e a diminuição do tempo de internação.

O estudo de Valladares (2009), cujo objetivo foi analisar os efeitos da utilização da arte-terapia com crianças hospitalizadas, identificou que não houve informações suficientes que comprovassem que a arte-terapia pudesse reduzir o tempo de internação. Todavia, houve benefícios para a qualidade de vida das crianças, informação que vem ao encontro do discurso obtido, apesar de serem diferentes os recursos terapêuticos utilizados em cada estudo. A pesquisa também concluiu que a arte-terapia faz com que a criança aceite com maior naturalidade a hospitalização, levando-a a se adaptar mais facilmente à rotina hospitalar e a restabelecer seu equilíbrio emocional.

As crianças com câncer vivenciam muitas internações hospitalares, seja no agravamento da doença, seja para procedimentos terapêuticos, tal como quimioterapia, ou mesmo para tratamento de seqüelas provenientes da evolução da mesma (PFEIFER; MITRE, 2008). Caso o tempo de internação infantil seja muito prolongado, a criança hospitalizada pode desenvolver maiores transtornos comportamentais, o que prejudica sua qualidade de vida (VALLADARES, 2009).

Diante deste fato torna-se importante buscar estratégias que minimizem os fatores estressores da hospitalização. Garcia e Pfeifer (2009), em pesquisa realizada para analisar o impacto de caixas de histórias enquanto recurso terapêutico ocupacional no humor de crianças com câncer internadas, identificaram que, após a contação das histórias, $60 \%$ das crianças apresentaram mudança para um estado emocional mais feliz, reafirmando que recursos terapêuticos não medicamentosos, como as caixas de histórias, são boas estratégias de enfrentamento do câncer infantil, ajudando a combater os efeitos da hospitalização.

\section{Alegria e distração para a criança}

Depois da contação da história, as crianças parecem mais felizes devido ao aspecto positivo do programa, melhorando o humor e desenvolvendo a socialização. Percebemos o quanto as crianças ficam mais animadas 
e o quanto elas se divertem no mundo da criatividade e imaginação. Por elas estarem mais animadas, a alegria delas é transmitida a nós. Além disso, a alegria renova a energia dessas crianças, melhorando suas condições de saúde. Além disso, as histórias contadas fazem com que o tempo passe sem as crianças perceberem, ou seja, com o programa é mais fácil distraí-las.

O discurso obtido relatou a importância do "Programa de Extensão Caixa de Histórias" para a alegria, criatividade, imaginação e socialização das crianças com câncer hospitalizadas.

Notou-se que o termo "distração" foi utilizado mais uma vez pelos profissionais da saúde sem caráter terapêutico, no sentido de ocupar o tempo da criança para que ela não perceba a situação vivenciada, não sendo este o objetivo do "Programa de Extensão Caixa de Histórias", o qual, como já citado, auxilia no enfrentamento da hospitalização de crianças e adolescentes. Desta forma, é essencial que ocorra outro tipo de distração, em que, terapeuticamente, a criança seja estimulada a compreender o adoecimento e a hospitalização, refletindo sobre estratégias positivas para lidar com aquela situação, auxiliando, portanto, no enfrentamento da hospitalização.

O desenvolvimento da abordagem lúdica no hospital enfrenta algumas dificuldades, tais como o status rebaixado do brincar e dos profissionais que se utilizam deste recurso na cultura brasileira. Desta forma, o brincar passa a ser visto como algo sem importância e sem qualificação, produzindo ansiedade e culpa, como se o sofrimento fosse desvalorizado (FORTUNA, 2004).

No entanto, percebe-se o esforço de muitos no sentido de modificar tal situação, valorizando os procedimentos não medicamentosos. Além do "Programa de Extensão Caixa de Histórias" há a implantação de outros programas que utilizam a arte ou histórias como recurso terapêutico, levando alegria para crianças hospitalizadas, proporcionando a humanização hospitalar e o desenvolvimento da imaginação, tais como: "Doutores da Alegria" (MASETTI, 2005), "Companhia do Riso" (FRANÇANI et al., 2008), "Associação Viva e Deixe Viver" (GOUVEIA, 2003), entre outros. Outro ponto importante que essas iniciativas têm em comum é considerar a criança como sujeito, tratando-a com respeito á sua condição peculiar de pessoa em desenvolvimento, oferecendo a ela, através de recursos lúdicos, informações, esclarecimentos sobre seu estado e procedimentos, estimulando sua autonomia e a reconquista de atividades simples, mas fundamentais para sua identidade e saúde.

\section{Impacto pessoal}

As histórias contadas nos ajudam na realização das nossas atividades, nos distraem e, desta forma, sorrimos com as crianças. Necessitamos que a criança dialogue conosco e, após o programa, elas ficam mais comunicativas.

A equipe de saúde que trabalha no campo da Oncologia Pediátrica vivencia situações de sofrimento, dor, perda, com grande impacto emocional. Todos esses fatores podem levar ao estresse profissional ou burnout. Podem, então, surgir as seguintes problemáticas com estes profissionais: falta de suporte psicológico, estresse com o diagnóstico, tratamento e possibilidade da morte nessa área, despreparo para lidar com a família, sentimento de desânimo, impotência ou abandono, entre outras (RAMALHO et al., 2007).

O "Programa de Extensão Caixa de Histórias", apesar de não ser direcionado aos profissionais de saúde que atuam na enfermaria pediátrica, acaba sendo benéfico a estes, uma vez que facilita a realização das atividades da equipe.

Além disso, recursos terapêuticos não medicamentosos, tal como a leitura mediada de contos infantis, podem ser considerados boas estratégias de humanização para os membros da equipe de saúde (MORENO et al., 2003). Através da contação de histórias, é possível que os profissionais da saúde compreendam melhor os sentimentos e necessidades de crianças internadas, melhorando a qualidade da assistência (CERIBELLI et al., 2009) e, conseqüentemente, o estresse profissional diminui.

\section{CONCLUSÕES}

Através dos dados obtidos nesta pesquisa, concluiuse que os profissionais de saúde que atuam no cuidado da criança com câncer ainda não compreendem os verdadeiros objetivos do "Programa de Extensão Caixa de Histórias", restringindo-o, em alguns momentos, a uma técnica de distração, enquanto estes realizam suas funções. No entanto, percebeu-se que as 'caixas de histórias' são importantes recursos terapêuticos para o enfrentamento do câncer infantil, melhorando a qualidade da internação, trazendo alegria para as crianças, ajudando a combater os efeitos da hospitalização e facilitando a recuperação da criança. Além disso, a contação de histórias facilita a realização de procedimentos médicos e de enfermagem e ajuda a equipe de saúde na realização de suas atividades.

Portanto, notou-se que a equipe de saúde está envolvida no cuidado à criança com câncer, acreditando na eficácia e incentivando as práticas do Programa de Extensão "Caixa de Histórias". Como já existe uma credibilidade no programa por parte da equipe de saúde, é necessário haver práticas no sentido de esclarecer melhor seus objetivos para 
que se reflita sobre sua importância terapêutica, facilitando a atuação multidisciplinar no câncer infantil. Além disso, é essencial que tal temática seja incentivada no campo das políticas públicas relacionadas à saúde da criança no sentido de promover conhecimentos sólidos acerca da hospitalização infantil.

GARCIA, N. R.; PFEIFER, L. I.; PANÚNCIO-PINTO, M. P. The stories box behind the vision health professionals as a strategy to coping of infant hospitalization. Rev. Ter. Ocup. Univ. São Paulo, v. 23, n. 2, p. 169-177, maio/ago. 2012.

\begin{abstract}
The "Program of Stories Box Extension" has been developed in pediatric wards, using as resources puppets and others elements. The aim of this study was to analyze the opinion of health's professionals about this program. Five health's professionals of oncology pediatric ward have been participated, which answered a questionnaire about the impact of "Stories Box" in children hospitalized. Was used the Discourse of the Collective Subject for analysis. The answers permitted the follow collective discourse: "The stories, and any kind of plays activities, help in recovering of child, allowing that she/he forgets her/him suffering. This way, this children stay more feel at ease, decreasing the discomfort caused for hospital ambience. We believe that stories improve the quality of hospitalization, because we realize how children became more animated and how they entertain themselves in the world of creativity and imagination. How they are livelier, the joy of them is transmitted to us. The stories told helped us in our activities, amusing us and, this way, smiling with children. So, time passes without them realizing".
\end{abstract}

KEY WORDS: Humanization of assistance; Patient care team; Medical oncology/manpower; Child; Health personnel/manpower; Child health services/manpower.

\section{REFERÊNCIAS}

ADAM, P.; HERLICH, C. Sociologia da doença e da medicina. Bauru: Edusc, 2001.

ALVES, A. L. A.; PFEIFER, L. I.; BEZERRA, J. R.; SANTOS, V. M. D. Caixa de histórias: um recurso terapêutico ocupacional utilizado em enfermarias de um hospital terciário no interior de São Paulo. In: CONGRESSO BRASILEIRO DE TERAPIA OCUPACIONAL, 10., Goiânia, 2007. Anais... Goiânia: Kelps, 2007.

BACKES, D. S.; LUNARDI FILHO, W.; LUNARDI, V. L. O processo de humanização do ambiente hospitalar centrado no trabalhador. Rev. Esc. Enferm. USP. São Paulo, v. 40, n.2, p. 221-227, 2006.

CERIBELli, C.; NASCIMENTO, L. C.; PACÍfICO, S. M. R.; LIMA, R. A. G. A mediação de leitura como recurso de comunicação com crianças hospitalizadas. Rev. Latino-Am. Enferm., Ribeirão Preto, v. 17, n. 1, p.81-87, 2009.

D'ALCANTARA, E. B. Criança Hospitalizada: o impacto do ambiente hospitalar no seu equilíbrio emocional. Rev. Virt. Psico. Hosp. Saúde, Belo Horizonte, v. 6, p. 38-55, 2008.

FONTES, C. M. B.; et al. Utilização do brinquedo terapêutico na assistência à criança hospitalizada. Rev. Bras. Educ. ESPEC., Piracicaba, v. 16, n. 1, p. 95-106, 2010.
FORTUNA, T. R. Brincar viver aprender: educação e ludicidade no hospital. Ciênc. Letras, Porto Alegre, n. 35, p. 185-201, 2004.

FRANÇANI, G. M.; ZILIOLI, D. SILVA, P. R. F.; SANT'ANA, R. P. M.; LIMA, R. A. G. Prescrição do dia: infusão de alegria. Utilizando a arte como instrumento na assistência à criança hospitalizada. Rev. Latino-Am. Enferm., Ribeirão Preto, v. 6, n. 5, p. 27-33, 1998.

GARCIA, N. R; PFEIFER, L. I. O uso de caixas de histórias em uma enfermaria oncopediátrica: a visão de crianças internadas. In: CONGRESSO BRASILEIRO DE TERAPIA OCUPACIONAL, 11., Fortaleza, 2009. Anais... Fortaleza, 2009.

GOMES, I. L. V.; CAETANO, R.; JORGE, M. S. B. Conhecimento dos profissionais de saúde sobre os direitos da criança hospitalizada: um estudo exploratório. Ciênc. Saúde Coletiva, v. 15, n. 2, p. 463470, 2010.

GOUVEIA, M. H. Viva e deixe viver: histórias de quem conta histórias. São Paulo: Globo, 2003.

LEFÉVRE, F.; LEFÉVRE, A. M. C. O sujeito coletivo que fala. Interface Comun. Saúde Educ., Botucatu, v. 10, n. 20, p. 517524, 2006.

LEFÉVRE, F.; LEFÉVRE, A. M. C.; MARQUES, M. C. C. 
Discurso do sujeito coletivo, complexidade e auto-organização. Ciênc. Saúde Coletiva, v. 14, n. 4, p. 1193-1204, 2009.

LEFÉVRE, F.; LEFÉVRE, A. M. C.; TEIXEIRA, J. J. V. $O$ discurso do sujeito coletivo: uma nova abordagem metodológica na pesquisa qualitativa. Caxias do Sul: EDUCS, 2002.

LEITE, T. M.; SHIMO, A. K. O brinquedo no hospital: uma análise da produção acadêmica dos enfermeiros brasileiros. Rev. Enf. Esc. Anna Nery, Rio de Janeiro, v. 11, n. 2, p. 343-350, 2007.

LIMA, R. A. G.; et al. A arte do teatro Clown no cuidado às crianças hospitalizadas. Rev. Esc. Enferm. USP, São Paulo, v. 43, n. 1, p.186-193, 2009.

MARTINS, M. R.; RIBEIRO, C. A.; BORBA, R. I. H.; SILVA, C. V. Protocolo de preparo da criança pré-escolar para punção venosa, com utilização do brinquedo terapêutico. Rev. Latino-Am. Enferm., Ribeirão Preto, v. 9, n. 2, p.76-85, 2001.

MASETTI, M. Doutores da ética da alegria. Interface Comun. Saúde Educ., Botucatu, v. 9, n. 17, p. 453-458, 2005.

MICELI, A. V. P. Dor em crianças com câncer. Rev. Dor. São Paulo, v. 6, n. 3, p. 606-13, 2005.

MITRE, R. M. A. Brincando para viver: um estudo sobre a relação entre a criança gravemente adoecida e hospitalizada e o brincar. Rio de Janeiro, 2000. Dissertação (Mestrado) - Instituto Fernandes Figueira, FIOCRUZ, 2000.

MITRE, R. M. A.; GOMES, R. A perspectiva dos profissionais de saúde sobre a promoção do brincar em hospitais. Ciênc. Saúde Coletiva, v. 12, n. 5, p. 1277-1284, 2007.

MITRE, R. M. A.; GOMES, R. A promoção do brincar no contexto da hospitalização infantil como ação de saúde. Ciênc. Saúde Coletiva, v. 9, n. 1, p. 147-154, 2004.

MORENO, R. L. R.; DINIZ, R. L. P.; MAGALHÃES, E. P.; SOUZA, S. M. P. O.; SILVA, M. S. A. Contar histórias para crianças hospitalizadas: relato de uma estratégia de humanização. Pediatria, São Paulo, v. 25, n. 4, p. 164-169, 2003.

NASCIMENTO, L. C.; PEDRO, I. C. S.; POLETI, L. C.; BORGES, A. L. V.; PFEIFER, L. I.; LIMA, R. A. G. L. O brincar em sala de espera de um Ambulatório Infantil: a visão dos profissionais de saúde. Rev. Esc. Enferm. USP, São Paulo, v. 45, n. 2, p.465-472, 2011.

PAPALIA, D. E; OLDS, S. W; FELDMAN, R. D. Desenvolvimento humano. Porto Alegre: Artmed, 2006.

PARCIANELLO, A. T; FELIN, R. B. E agora doutor, onde vou brincar? Considerações sobre a hospitalização infantil. Bárbaro,
Santa Cruz do Sul, n. 28, p. 147-166, 2008.

PARHAM, L. D; PRIMEAU, L. A. Recreação e terapia ocupacional. In: PARHAM, L .D; FAZIO, L. S. (Orgs.). $A$ Recreação na terapia ocupacional pediátrica. Trad. Maria de Lourdes Gianinni. São Paulo: Santos Editora, 2002.

PEDROSA, A. M.; MONTEIRO, H.; LINS, K.; PEDROSA, F.; MELO, C. Diversão em movimento: um projeto lúdico para crianças hospitalizadas no Serviço de Oncologia Pediátrica do Instituto Materno Infantil Prof. Fernando Figueira, IMIP. Rev. Bras. Saúde Matern. Infant., Recife, v. 7, n. 1, p. 99-106, 2007.

PEREIRA, A. P.; PFEIFER, L. I.; PANÚNCIO-PINTO, M. P. Caixas de histórias facilitando o envolvimento entre universidade e comunidade. In: SIMPÓSIO APRENDER COM CULTURA E EXTENSÃO, 1, Ribeirão Preto, 2009. Anais... Ribeirão Preto, 2009.

PFEIFER, L. I. ; DELSIM, J. C. ; SANTOS, V. M. D. ; MARTINS, Y. D. Contar história: uma abordagem terapêutica ocupacional no auxilio À criança hospitalizada. In: CONGRESSO NORTE NORDESTE DE TERAPIA OCUPACIONAL, 6, 2006, Maceió. Anais... Maceió: Associação dos Terapeutas Ocupacionais de Alagoas, 2006.

PFEIFER, L. I.; MITRE, R. M. A. Terapia Ocupacional, dor e cuidados paliativos na atenção à infância. In: DE CARLO, M. M. R. P.; QUEIROZ, M. E. G. (Org.). Dor e cuidados paliativos: terapia ocupacional e interdisciplinaridade. São Paulo: Roca, 2008, p. 258-287.

RAMALHO, M. A. N.; NOGUEIRA-MARTINS, M.C.F. Vivências de profissionais de saúde da área de oncologia pediátrica. Psicol. Estud., Maringá, v. 12, n. 1, p. 123-132, 2007.

SANTOS, V. M. D. Análise do processo de capacitação do graduando de terapia ocupacional para atuar junto a crianças hospitalizadas através de caixas de histórias. Ribeirão Preto, 2008. [Monografia] - Faculdade de Medicina de Ribeirão Preto, Universidade de São Paulo, 2008.

SOARES, V. V.; VIEIRA, L. J. E. S. Percepção de crianças hospitalizadas sobre realização de exames. Rev. Esc. Enferm. USP, São Paulo, v. 38, n. 3, p. 298-306, 2004.

VALLADARES, A. C. A. A arteterapia humanizando os espaços de saúde. São Paulo: Casa do Psicólogo, 2009.

VALLE, E. R. M. Câncer infantil: compreender e agir. Campinas: Editora Psy, 1997. 